\title{
O tempo ficcional literário e seus modelos
}

\section{Fictional time in \\ literature and its models}

Autor: Andrei Kofman

Edição: RUS Vol. 11. № 17

Data: Dezembro de 2020 


\section{O tempo ficcional literário e seus}

modelos

\section{Andrei Kofman*}

Resumo: 0 artigo descreve as características do tempo artístico na literatura e seus modelos básicos, enquanto as disposições teóricas são ilustradas por exemplos da literatura russa. A especificidade do tempo artístico é revelada em comparação com o tempo objetivo. Mostra-se que as principais características do tempo objetivo, como a objetividade, a linearidade, a irreversibilidade, a monotonia e a continuidade no tempo artístico, não são mantidas, pois o tempo é sempre subjetivo. Isso é evidente na análise do modelo de tempo histórico, que afirma reproduzir o tempo objetivo. A seguir, consideramos quatro modelos de tempo mais usados na literatura: o tempo mitológico, que se distingue por seu caráter cíclico; 0 tempo reversível, que se move do presente para o passado; o modelo de atemporalidade ou tempo parado; e o modelo de tempo integrador, que representa, numa unidade indivisível, o passado, o presente e o futuro existentes.

\begin{abstract}
The article describes the characteristics of artistic time in literature and its main models, illustrating them by examples from Russian literature. The specificity of artistic time is revealed in comparison with objective time. It is shown that the main features of objective time, such as objectivity, linearity, irreversibility, monotony and continuity in artistic time are not maintained, because it is always subjective time. This is evident when we analyze the historical time model, which claims to reproduce objective time. Next, we describe four more time models that are most commonly used in literature: mythological time, which is distinguished by its cyclic character, reversible time, moving from the present to the past, the model of stopped time and the integrating time model, which represents the existing past, present, and future in an undifferentiated unity.
\end{abstract}

Palavras-chave: Tempo objetivo; Tempo subjetivo; Tempo histórico; Tempo mitológico; Tempo reversível; Modelo da atemporalidade; Tempo integrador

Keywords: Objective time; Subjective time; Historical time; Mythological time; Reversible time; Atemporality model; Integrating time. 


\section{O tempo objetivo e o tempo subjetivo}

* Doutor em Filologia, Professor Titular, Vice-diretor do Instituto A. M. Gorky de Literatura Mundial da Academia Russa de Ciências (IMLI Rossískaia Akadiémia Nauk), de Moscou, Rússia. E-mail: andrey.kofman@gmail.com
Para compreender as particularidades do tempo literário, énecessário distinguir as características físicas básicas do tempo real terrestre, em cujo cotidiano está engajada a vida humana, medida pelos ponteiros implacáveis do relógio. Esse tempo é objetivo, ou seja, não depende da vontade do ser humano, nem de sua relação com ele, nem de sua aceitação dele; se, por um lado, o ser humano é capaz de modificar e reestruturar o espaço terrestre, por outro, por enquanto, ele não é senhor do tempo. Além disso, o tempo objetivo caracteriza-se como linear e sequencial, ou seja, um dia após o outro, um mês após o outro, um ano após o outro, e corre apenas em uma única direção, partindo do passado, percorrendo o implacável instante presente e encaminhando-se ao futuro - nunca de outro modo. Por força disso, o tempo objetivo é irreversível: não podemos fazer com que ele volte atrás, por mais que assim desejemos. Outra característica do tempo objetivo é a monotonia, que pressupõe a possibilidade de medição: ele (sublinhamos que se trata aqui do tempo terrestre e não do cósmico) corre sempre em determinada velocidade; não é possível apressá-lo, retardá-lo ou pará-lo. Em consequência disso, ele tem também outra propriedade evidente: o caráter ininterrupto.

Podemos falar também, com pleno direito, na existência de um tempo subjetivo, ou seja, o tempo objetivo refratado pela percepção humana. Desse modo, passando pelo prisma da consciência humana, o tempo pode mudar inteiramente todas as suas características. A própria noção de "subjetivo", em contraposição a "objetivo" já diz que esse tempo, ainda que não seja controlável, de qualquer modo depende por completo da psique e da individualidade do ser humano. O tempo pode perder a qualidade da linearidade e tornar-se reversível; isso acontece, por exemplo, quando uma pessoa mergulha em lembranças e revive o passado. Além disso, o tempo subjetivo pode ser apressado ou retardado, situação que cada um de nós, sem dúvida, já experimentou mais de uma vez na vida. A imagem clichê "o instante pareceu-lhe uma eternidade" nasceu 
da experiência direta do sofrimento: em momentos de perigo, de forte tensão emocional, em situações de ansiedade, preocupação ou indeterminação, o tempo realmente se arrasta, e um minuto pode parecer uma hora. Igualmente enraizado na psicologia real está o provérbio russo (originário da comédia de Griboiédov A inteligência, que desgraça!):! "quem é feliz não sente o passar das horas", que constata a compressão do tempo. Pessoas profundamente mergulhadas no processo artístico também "não sentem o passar das horas". Finalmente, o tempo subjetivo é descontínuo, pois o sono sem sonhos é uma ruptura no tempo, isso sem falar nos estados de perda dos sentidos. É importante sublinhar o fato de que o tempo subjetivo, esse tempo imaginário, existente só na consciência do indivíduo, torna-se, para a própria pessoa, até mais significativo e real do que o tempo objetivo.

A literatura ficcional apresenta-se como reflexo duplo da consciência individual: ela reconstitui, de um lado, a personalidade dos heróis, de outro, a individualidade do autor. Assim o tempo subjetivo torna-se parte indissociável da literatura ficcional. Ademais, no seio da literatura formaram-se diversos modelos de tempo ficcional essencialmente diferentes do tempo objetivo ou então abertamente opostos a ele. Desses modelos do tempo artístico poderíamos destacar um grande número. Entretanto, caracterizaremos aqui, brevemente, apenas os mais significativos e mais disseminados.

\section{Modelos do tempo ficcional}

\section{O tempo histórico}

É claro que o modelo mais disseminado, tradicional, universalmente aceito na literatura é aquele que pode ser designado pela expressão "tempo histórico". A principal propriedade desse modelo ficcional é a disposição sequencial dos aconte-

1 Tradução de Polyana de Almeida Ramos na dissertação "Gorie ot uma, de Aleksandr Griboiédov - Tradução e aproximações”. São Paulo, USP, 2011, p. 189. 
cimentos na ordem em que eles ocorreram, sem nenhum tipo de perturbação cronológica e com base na plena fidedignidade da série de acontecimentos relatada. Em todo caso, sem dúvida, foi exatamente nos limites do tempo histórico que se desenvolveu, no início, o romance europeu. Na prosa literária, o modelo do tempo histórico encontra-se tão disseminado e é tão amplamente utilizado que quaisquer desvios em relação a ele eram entendidos como desenfreada inovação - e foi assim desde o seu surgimento, na época do romantismo.

O modelo de tempo ficcional histórico pretende reproduzir com fidedignidade o tempo objetivo em todos os seus parâmetros físicos. Mas essa semelhança aparente, na verdade, revela-se uma completa ficção; além disso, justamente no modelo de tempo ficcional histórico manifesta-se, com maior nitidez, as diferenças essenciais entre o tempo ficcional, reconstituído na literatura, e o tempo objetivo. De fato, se tomarmos cada traço do tempo objetivo, observaremos como, na literatura, ele se transforma radicalmente.

Vamos começar pela seguinte qualidade do tempo objetivo: o seu caráter ininterrupto. O modelo de tempo ficcional histórico, por princípio, não pode ter um caráter ininterrupto, pois o escritor não descreve a vida do herói dia após dia, hora após hora, minuto após minuto. Do fluxo ininterrupto do tempo, ele é obrigado a selecionar certos acontecimentos importantes para a biografia do herói, "saltando" de um a outro. Veja o caso das memórias, do livro autobiográfico, como, por exemplo, Infância, de Tolstói ou de Gorki. Considerando essas obras a partir desse ponto de vista, logo ficará claro que o autor, por mais minucioso que tenha sido, foi obrigado a interromper o curso do tempo, escolhendo os momentos mais significativos.

Entretanto, justamente por isso o tempo histórico perde também a qualidade da uniformidade, ou seja, ele é capaz de se contrair e de se ampliar. $O$ recurso mais evidente de aceleração do tempo histórico é a utilização de fórmulas do tipo "passaram-se dois anos"; mas, inclusive quando essas fórmulas não são aplicadas, a passagem de um espaço de tempo significativo (um caso característico é o epílogo) consiste num 
modo de aniquilamento do tempo objetivo. Exemplos do contrário, ou seja, da distensão do tempo no âmbito do modelo histórico também podem ser encontrados em grande quantidade; por exemplo, quando acontecimentos ocorridos em um minuto são descritos em um texto cuja leitura ocupa vários minutos. Um exemplo claro desse tipo de distensão do tempo é apresentado no romance Crime e Castigo, de Dostoiévski, cuja parte principal abrange quatro dias; em contraposição, no mesmo romance, um ano e meio são comprimidos numa única frase - (Epílogo, primeiro parágrafo): "Desde o dia do seu crime transcorreu quase um ano e meio". ${ }^{2}$ Ressaltamos: também nesse caso funciona inteiramente o princípio da elegibilidade, ou seja, o autor, por vontade própria, interrompe o tempo, escolhendo uma série de acontecimentos e, do mesmo modo, de acordo com seu próprio entendimento, contrai e amplia o tempo.

Se assim é, então o tempo histórico na literatura não pode ser objetivo, ele sempre depende da individualidade do autor, ele é sempre subjetivo. Finalmente, ainda quando o autor segue a ordem cronológica, o tempo histórico pode ser também reversível e, além disso, numa mão dupla. Quando o herói lembra o passado, não é isso um voltar no tempo? E se o leitor estiver relendo um romance histórico, isso também não seria uma volta no tempo ficcional, do final ao começo, sem falar no fato de que essa volta pode acontecer quantas vezes ele quiser? Desse modo, o tempo histórico ficcional perde também a característica da linearidade. Do que foi dito, podemos concluir que o tempo, na literatura de ficção, é sempre um tempo subjetivo, seja qual for o modelo em que ele se apresente, e, como tal, ele é caracterizado por todos os recém-mencionados aspectos do tempo subjetivo.

Nos limites do modelo do tempo histórico, destaca-se o tempo épico, apresentado no gênero folclórico de muitos povos. Quando ele se constrói com base na disposição sequencial dos acontecimentos, encontram-se presentes alguns traços característicos: a sua ação, via de regra, acontece num passa-

2 Dostoiévski, F. M. Crime e castigo. Trad. Paulo Bezerra. São Paulo: Editora 34, 2009, p. 543. 
do muito distante, às vezes mitológico; não há uma cronologia precisa ligada às datas históricas; são abarcados períodos de tempo muito significativos - décadas - e assim a vida de algumas gerações. Além disso, o tempo épico sempre é preenchido por acontecimentos muito significativos, que extrapolam bastante os limites dos destinos pessoais, e não importa se esses acontecimentos são históricos ou mitológicos; via de regra, ele recompõe épocas decisivas e intensas da vida de uma etnia. $O$ tempo épico é um tempo de Feitos, de heroísmo, de reformas, de potentes colisões, com significado fatal tanto para os indivíduos quanto para o povo como um todo.

Reproduzido no seio da literatura profissional, isto é, escrita por escritores profissionais, em contraposição à narrativa folclórica, o tempo épico conservou apenas essas últimas características, tendo perdido as duas anteriores, ou seja, adquiriu uma historicidade verificada e uma cronologia precisa. $\mathrm{O}$ exemplo clássico é Guerra e paz, de Tolstói: a ação do romance, que se passa de 1805 a 1819, não apenas se mostra longamente estendida no tempo, mas, principalmente, reconstrói uma série de acontecimentos históricos importantes, dos quais dependeu o destino da Rússia. Destinos isolados são engajados na potente corrente da história; a guerra com os franceses é tratada como um grandioso Feito coletivo e, embora no romance estejam refletidos tanto a vileza quanto a covardia e o carreirismo de personagens específicos, nem por isso o Feito perde o seu autêntico caráter heroico, nem o tempo artístico, a sua envergadura verdadeiramente épica. Na literatura russa, esse modelo temporal foi reproduzido mais tarde em três romances da época soviética: $O$ Don silencioso, de Mikhail Chólokhov (dedicado à Revolução de 1917 e à guerra civil), Vivos e mortos, de Konstantin Símonov, e Vida e destino, de Vassíli Grossman (dedicados à Segunda Guerra Mundial).

\section{O tempo mitológico}

Esse modelo temporal nasceu na mitologia dos mais diversos povos, de onde, sem dúvida, em forma transfigurada, foi adotado pela literatura profissional, principalmente no século 
XX. A percepção específica do tempo pela consciência mitológica está suficientemente descrita em trabalhos de muitos cientistas, inclusive russos. Uma lista de alguns trabalhos fundamentais sobre este assunto é apresentada na nota de rodapé pela ordem cronológica de publicação. ${ }^{3} \mathrm{Na}$ qualidade de traços básicos que compõem o tempo mitológico, destacam-se duas de suas particularidades. A primeira é a retomada da época primitiva: como escreveu Eleazar Meletínski, "esse é o tempo dos primeiros objetos, das primeiras ações e da primeira criação, ele está refletido, acima de tudo, nos mitos da criação - cosmogônicos, antropológicos e etnogônicos". ${ }^{4}$ Segundo Mircea Eliade, o tempo mitológico tem o objetivo de "anular o tempo decorrido, de abolir a história por meio da volta constante a tempos imemoriais, por meio da repetição do ato cosmogônico".$^{5} \mathrm{Ou}$ seja, o ser humano gravita constantemente em torno da volta ao passado, exatamente ao ponto primordial do passado em que o cosmos surgiu do caos. Dessa particularidade decorre organicamente outra: o caráter cíclico do tempo mitológico, que se organiza pela repetição arquetípica de ações e rituais que levam o ser humano eternamente de volta à época mitológica da primeira criação. $O$ tempo mitológico está estreitamente relacionado com o ciclo da natureza e, em essência, o reproduz.

Nessas duas características, o tempo mitológico opõe-se nitidamente ao tempo histórico objetivo: o seu caráter cíclico e repetitivo nega a linearidade e o sequenciamento; ademais, ele se coloca em contraposição à irreversibilidade do tempo objetivo.

Não por acaso, precisamente no século XX, surgiu um intenso interesse pela mitologia, pela consciência prerracionalis-

3 Gurevitch, A. Ia. Kategorii srednevekovoi kulturi. Moscou, 1972; Levi-Briul, L. Pervobitnoie michliéniie. Leningrado, 1930; Lotman, lu. M. "Proiskhojdeniie siujeta v tipologuitcheskom osveschenii". In Stati po tipologuii kulturi: V 2 t. Tartu, 1973. T. 2; Meletinski, le. M. Poetika mifa. Moscou, 1976; Steblin-Kamenski, M. I. Mif. Moscou, 1976; Freidenberg, O. M. Mif i literatura drevnosti. Moscou, 1978; Eliade, M. Siiashchennoye i mirskoie. Moscou, 1994; Eliade, M. Aspekti mifa. Moscou, 1995; Khiubner, K. Istina mifa. Moskva, 1996; Meletinski, le. M. Ot mifa k literature. Moscou, 2001

4 Mifi narodnogo mira. Moscou, 1980, tom 1, p. 252.

5 Eliade, M. Kosmos i istoriia. Moscou, 1987, p. 88. 
ta, pelo homem "primitivo". Esse interesse foi gerado, acima de tudo, pela crise do positivismo, com sua fé inquebrantável no desenvolvimento progressivo da história, na benesse do progresso técnico-científico e na possibilidade de uma compreensão racional e de uma reforma do mundo. As arrasadoras guerras mundiais geraram decepção com os valores da civilização ocidental e perda do otimismo da sociedade. A fé positivista no progresso ruiu, gerando na consciência do homem ocidental o temor do futuro e aquele estado de espírito mental específico que M. Eliade denominou de "pavor da história". Em todo caso, é indiscutível que o "pavor da história" (história que, no século $\mathrm{XX}$, mostrou-se mais terrível, em número de vítimas, do que em qualquer época anterior) obrigou o homem ocidental a avaliar de outro modo, como demonstrou o próprio Eliade, a consciência primitiva, com seu caráter atemporal e arquetípico, com sua invejável estabilidade.

Por força desses motivos, o modelo artístico do tempo mitológico disseminou-se muito amplamente na literatura da Europa Ocidental no século XX - podemos citar Thomas Mann, Franz Kafka, James Joyce, os vanguardistas. Para estes últimos, o caráter sedutor do tempo mitológico condicionava-se, em grande medida, pela enorme importância adquirida pelo tema do passado na literatura de vanguarda. A aspiração à "volta às origens", a fazer renascer uma "protolíngua", um "balbucio primitivo", é um dos paradigmas mais invariáveis da consciência artística de vanguarda, claramente manifesta também no modernismo brasileiro.

Ao mesmo tempo, o modelo de tempo mitológico se evidenciou muito antes na literatura autoral: é possível que esse modelo tenha sido reproduzido pela primeira vez por Púchkin, em seu famoso poema $O$ Cavaleiro de Bronze. Também são dignos de nota os procedimentos artísticos inovadores com que ele criou este modelo.

É impossível penetrar fundo no conteúdo desse poema genial sem compreender seu subtexto histórico. Para conformar a Rússia à maneira europeia, Pedro I conseguiu em longa guerra com os suecos (1700-1721) conquistar parte da costa do mar 
Báltico. Com o propósito de consolidar sua conquista, em 1703, ele fundou, na foz do rio Nievá, a nova capital do governo russo, a cidade de São Petersburgo. O local mostrara-se impróprio para edificações: clima rigoroso, bosques densos e pântanos extensos; mas Pedro não considerava dificuldades nem perdas humanas. Além disso, como se revelou depois, o Nievá transbordava periodicamente e, em 300 anos de sua história, São Petersburgo sofreu 270 inundações, em que as águas subiram mais do que 1,5 metro.

O poema contém muitos conflitos, mas, aqui, nosso foco está voltado para o conflito principal, que é expresso com impressionante laconismo já nos dois primeiros versos do poema:

"На берегу пустынных волн Стоял он, дум великих полн". ${ }^{6}$

"Na margem das ondas desertas

Estava ele, pleno de grandiosas ideias"

Nesses versos, por trás de cada palavra, esconde-se um campo semântico profundo. A "margem" indica o horizontal, o "baixo", mas também o espaço limítrofe entre a água e a terra, em que vai se desenrolar toda a ação do poema. $O$ adjetivo "desertas" indica a ausência de ser humano, mas, antes de tudo, a ausência de plenitude de conteúdo, e, nesse aspecto, indica a falta de sentido, de utilidade. A palavra "ondas" expressa o mundo de Proteu, ou seja, o mundo fluido, privado de formas rígidas. Três palavras criam a imagem integral de uma existência natural, caótica, sem sentido.

Cada palavra do verso seguinte consiste na antítese artística dessa imagem. Na tradução para o português, o verbo russo "stoial" perde, em parte, seu significado "ficava de pé", o que é uma pena, nesse contexto, ela encerra um sentido particular, que indica o vertical, em contraposição ao horizontal "da margem"; e o vertical, por si só, fornece outro sistema espacial de coordenadas, apontando o "alto" e o "baixo". "Ele", destacado em itálico, é o homem em oposição ao deserto; e "ele", solidificado na margem, também se contrapõe ao mundo de Proteu, móvel, mutável, privado da forma. As suas "grandiosas ideias"

6 A. S. Púchkin. Izbrannoie. Moscou, 1978, p.443. 
repudiam a falta de sentido do mundo natural, enquanto a palavra "poln" [pleno, cheio, repleto] sublinha a plenitude de conteúdo em contraposição ao vazio, ao hiato de sentido do espaço natural caótico. Diante de nós está o demiurgo na véspera do ato da criação do cosmos em lugar do caos.

As oposições, indicadas nos primeiros versos do "Cavaleiro de bronze", posteriormente se desdobram, multiplicam-se, aprofundam-se: examinando o poema palavra por palavra, verso por verso, não é difícil notar que todo ele está organizado de acordo com o princípio da antítese artística. Assim, no poema de Púchkin, criam-se duas imagens completas de mundos antípodas, que é oportuno designar como o mundo natural e o mundo cultural.

Podíamos pensar que, com a edificação da cidade, o princípio natural seria completamente esmagado, e o "elemento natural vencido" então se "submeteria" para sempre, como se fala na Introdução do poema. Mas não é assim. Como se esclarece depois, a vitória não foi definitiva, e o conflito encoberto entre os espaços antípodas irrompe à superfície, a sua descrição ocupa quase toda a primeira parte do poema.

Em plena medida, o sentido profundo do poema torna-se claro a partir da análise do tempo artístico do poema.

Ele começa nos primórdios, na primeira criação: no espaço fronteiriço, no ponto de junção das oposições, é proclamado $o$ ato demiúrgico da criação do mundo cultural. E eis que, contrariando a natureza, ergue-se a cidade, celebrada em palavras. Parece ter prevalecido a vitória definitiva contra o espaço natural, vitória que o poeta celebra em versos de louvor:

Красуйся, град Петров, и стой Неколебимо, как Россия, Да умирится же с тобой И побежденная стихия;

Вражду и плен старинный свой Пусть волны финские забудут И тщетной злобою не будут Тревожить вечный сон Петра!
Resplandeça, urbe de Pedro, e fique Firmemente, como a Rússia, Que a ti se resigne também A natureza enfim domada;

Seus ferros e o ódio velho Que as ondas finlandesas esqueçam E não turvem com inútil raiva O sono eterno de Pedro! 
Mas o que acontece depois? De repente, uma ruptura no tempo no verso seguinte: «Была ужасная пора/ о ней свежо воспоминанье...» (Era terrível esse tempo,/ é recente a sua memória...). Que tempo é esse? A natureza toma a cidade de assalto, desencadeia-se a batalha entre os mundos cultural e natural. Acontece o retorno aos primórdios, o tempo completa o círculo de seu curso. Além disso, indiscutivelmente, na consciência do poeta e dos leitores, está presente o fato de que as inundações acontecem periodicamente, quase todo ano, e que elas continuarão acontecendo no futuro; isso significa que o tempo caminha em círculos, voltando de novo e de novo ao ato arquetípico da criação. Desse modo, no poema, apresenta-se o modelo do tempo mitológico cíclico, que pressupõe que o conflito básico entre os mundos natural e cultural será reproduzido infinitamente, o que traz consigo a ideia da insolubilidade desse conflito por princípio.

\section{O tempo reversível}

A reversibilidade do tempo subjetivo manifesta-se, principalmente, em recordações: o mergulho mental no passado é uma marcha de volta no tempo, na contramão do movimento implacável dos ponteiros do relógio, é o restabelecimento de uma realidade já inexistente. Essa característica do tempo subjetivo tem um significado extremamente importante na vida do homem, relaciona-se com o elo entre presente e passado e é a personificação da memória, sem a qual seria impossível a própria existência da cultura. Por isso, na literatura, a reversibilidade do tempo subjetivo encontra sua mais ampla personificação na forma do modelo de tempo ficcional correspondente.

Ela se contrapõe ao tempo físico objetivo não apenas pelo parâmetro da reversibilidade, mas também por outros sinais: o tempo que retrocede pode correr irregularmente, ora se acelerando, ora se retardando, de acordo com o ritmo das recordações; ele pode ser interrompido (por exemplo, quando, volta e meia, as recordações do herói são interrompidas pela intromissão do presente); no final, também esse modelo de tempo 
está subordinado inteiramente ao princípio artístico da elegibilidade, ou seja, a memória sempre é seletiva, traz do passado apenas fragmentos isolados, os mais significativos. O tempo reversível é dinâmico por natureza: ele se concretiza no movimento do presente para o passado.

Não é difícil notar que o tempo mitológico tem uma série de traços comuns ao modelo temporal observado: em determinada "espiral", ele também se dirige para trás, também é dinâmico, ou seja, concretiza-se num movimento pelo trajeto presente-passado-futuro. Entretanto, entre esses modelos temporais, há uma série de diferenças essenciais. A mais importante consiste em que, no tempo mitológico, o movimento de volta ao passado chega, obrigatoriamente, a pontos mais profundos do tempo, tendo o objetivo de reproduzir arquétipos coletivos básicos. E, por isso, convém sublinhar o fato de que o tempo mitológico, embora subjetivo, não é individual: ele é sempre uma vivência coletiva do tempo, um produto da consciência coletiva. Como foi dito, o modelo do tempo mitológico tem em vista um perene movimento circular, que se projeta no futuro. Nesse sentido, o tempo mitológico é estável e imutável: qualquer perturbação do ciclo estabelecido traz a ameaça definitiva de sua completa desagregação.

O modelo do tempo reversível reproduz, antes de tudo, a vida da consciência individual, a recordação pessoal, o mergulho no próprio passado. Essa recordação pode resgatar as mais diversas camadas do passado, inclusive aquelas bem recentes. O movimento no tempo pode ter um caráter linear unidirecional e, nesse caso, ele adquire um sentido inteiramente diferente do retorno mitológico ao passado. Normalmente, esse movimento tem um caráter analítico: voltando ao passado, 0 herói ou escritor tenta se compreender como individualidade, talvez compreender o seu próprio povo, a sua raiz cultural etc.; de qualquer modo, isso não é a reprodução do arquétipo, mas um tipo próprio de investigação. No final, o modelo do tempo reversível é, em sua essência, instável e mutável, uma vez que a investigação do passado é feita com o objetivo de compreender o presente, enquanto a compreensão é um passo para a transformação. Por isso, nesse caso, via de regra, a volta ao 
passado tem o objetivo não de conservá-lo no futuro, mas de transformar o futuro.

O modo do tempo reversível raramente está presente na obra inteira; em geral, manifesta-se de modo esporádico, juntamente com outros modelos de tempo, com mais frequência interrompendo o tempo histórico.

No que se refere aos exemplos concretos do tempo reversível, não faz sentido mencionar aqueles casos em que o herói se lembra do seu passado - esse movimento do enredo é bastante comum e ocorre com frequência. É melhor prestar atenção a maneiras menos triviais de introduzir o tempo reversível. Na literatura russa, encontramos um exemplo impressionante desse procedimento artístico tão incomum no romance $O b$ lómov, de I. A. Gontcharov. A trama do romance se passa no modelo de tempo histórico, quando os acontecimentos são rigidamente organizados em ordem cronológica. Mas há um capítulo incomum, o IX, na primeira parte do romance, intitulado "O sonho de Oblómov". Este capítulo é introduzido da seguinte maneira: "O sonho interrompeu o fluxo lento e preguiçoso de seus pensamentos e de repente o transferiu para outra época, para outras pessoas, para outro lugar aonde seremos levados também e nós junto com os leitores do próximo capítulo". 0 sonho leva o protagonista à sua infância, que é recriada na forma de um paraíso perdido, mas ao mesmo tempo com uma abundância de pequenos detalhes cotidianos. Este capítulo é uma espécie de volta no tempo, de volta ao passado, ela é inteira apresentada no modelo de tempo reversível, pode-se dizer, tempo reverso; e, no capítulo seguinte, o romance retorna ao tempo histórico.

Outra variante de criação do modelo de tempo reversível, encontramos, por exemplo, na novela Khadji Murat, de L. Tolstói: no capítulo XXIII, o personagem da obra homônima ouve uma música folclórica e é levado pelo pensamento para os tempos antigos. Note-se que essa técnica é extremamente comum na literatura dos povos da antiga União Soviética, com sua tendência ao folclorismo. É fácil ver como o motivo do canto é importante nelas, como ele é ampliado e acentuado. Cantar 
ou escutar o canto, a música, é um ato sagrado, cujo objetivo principal é fazer a pessoa voltar ao passado e, dessa maneira, entender melhor sua base cultural.

\section{Modelo da atemporalidade}

Esse modelo artístico é apresentado em duas soluções figuradas ou variantes básicas: o tempo parado e o tempo imóvel, inexistente. Essas variações são idênticas em muitos aspectos, uma vez que ambas se baseiam na negação do movimento do tempo. Entretanto, uma vez que ele corre do passado ao futuro, passando pelo presente, então o passado e o futuro são negados ou, de certa forma, são riscados da consciência, e, em resultado disso, sobra um presente imóvel. Como se vê, o modelo da atemporalidade contrapõe-se ao tempo histórico objetivo, com seu movimento linear irreversível. Em parte, é justamente por isso que se justifica a sua disseminação na literatura do século XX.

Examinemos as diversas variantes desse modelo de tempo ficcional. Com certeza, ao recriar a realidade artisticamente, 0 escritor não é capaz de excluir por completo o modelo europeu "normativo" nem mesmo quando interpreta o tempo histórico de modo negativo. Mas, nesse momento, ele sente a necessidade de indicar e separar alguns estados anômalos específicos do herói, que permitem "abolir" o tempo histórico ainda que apenas um pouco. $O$ modelo da atemporalidade na variante do tempo estabelecido é convocado a transmitir justamente essa sensação. Geralmente, ele descreve estados particulares e relativamente curtos do herói, quando este, em momentos de suprema felicidade, iluminação, epifania ou, ao contrário, de terríveis sofrimentos, perde a noção do tempo, e sente que um instante do presente se estende durante uma eternidade.

Tiutchiev transmitiu maravilhosamente esse estado nos versos: "Так в жизни есть мгновения,/ Их трудно передать,/ Они самозабвения/ Земного благодать" (Pois na vida há instantes/ Difíceis de transmitir/ Eles são a bem-aventuran- 
ça /da abnegação terrestre). ${ }^{8} \mathrm{~A}$ "abnegação" encerra, inclusive, a abolição do movimento do tempo e a sensação do presente infindável.

De fato, com maior frequência, é a natureza, atuando sobre a consciência do herói, que consegue se livrar do senso do tempo, pois, com seu caráter inabalável, o mundo da natureza repudia a história. Nessa variante, o modelo da atemporalidade expressa a aspiração do artista a buscar essências básicas, valores eternos, pilares inabaláveis, em oposição ao caráter mutável e inconstante do mundo histórico.

Outra variante do modelo da atemporalidade, assinalada como um tempo imóvel ou inexistente, pressupõe não uma breve perda do senso de tempo, mas um tipo de modus vivendi, de meio de vida próprio, que nega o curso do tempo. Esse modelo de tempo imóvel é proprio do paraíso terrestre, do idílio, da utopia, em suas personificações tanto mitológicas quanto literárias.

Desde tempos antigos, na cultura de muitos povos, formaram-se mitos sobre longínquas ilhas da felicidade, situadas em mares desconhecidos, onde as pessoas não conheciam problemas nem preocupações, nem mesmo a preocupação fundamental: a ameaça do tempo implacável. Pois o tempo é o inimigo da bem-aventurança, já que ele logo trará ao homem a velhice, as doenças e a morte. Calculava-se que lá o tempo corria de outro modo ou, em geral, ficava imóvel; lá reinava a primavera eterna e não havia as mudanças do dia e da noite, o sol nunca se punha. Isso quer dizer que lá não existia nem "ontem" nem "amanhã", nem passado nem futuro, nem pesar pelo passado nem medo do que estava por vir, havia apenas a alegria permanente do presente.

Encontramos um excelente e surpreendente exemplo da personificação literária do modelo da atemporalidade em sua variante "paradisíaca" na novela de N. Gógol "Senhores de terra à moda antiga".

Na maior parte da novela há uma descrição da vida cotidiana do casal de velhos Pulkhéria Ivánovna e Afanássi Ivánovitch,

8 F. I. Tiúttchev. Izbrannoie. Moscou, 1974, p. 49. 
que habitam na sua propriedade rural. A descrição do mundo doméstico ocupa parte esmagadora da novela e, além disso, é feita com tanto cuidado, com tal quantidade de detalhes pitorescos que, na consciência do leitor, apresenta-se incomparavelmente maior, incomparavelmente mais significativa do que o mundo externo, merecedor apenas de algumas frases. Nas descrições dessa vida, chama atenção a utilização constante, quase impertinente, dos qualitativos "tranquilo", "bom", "agradável" e outros do mesmo campo semântico. Os cônjuges apresentam-se como pessoas absolutamente sem pecados, como crianças puras e ingênuas e, além disso, completamente naturais em todas as suas manifestações. Gógol chama a vida deles de "bucólica", e essa caracterização esclarece definitivamente o fundo mitológico tanto dos heróis quanto do espaço que eles habitam.

E o espaço paradisíaco, utópico, só pode existir completamente isolado do mundo real. O paraíso não suporta a história, o acontecimento, pois a bem-aventurança, em sua essência, é uniforme e sem acontecimentos; ele não suporta o movimento do tempo, que traz a morte. Vejamos, nesse aspecto, o tempo ficcional da novela em sua primeira parte, aquela em que é descrita a plácida existência do casal. Daremos atenção a alguns detalhes essenciais, para mostrar com que habilidade Gógol cria um modelo de atemporalidade.

Embora formalmente a ação da novela aconteça no passado, Gógol cria, com primor, tal construção temporal que o leitor toma o acontecido como presente, que se desenrola diante de seus olhos. Essa impressão é criada já nas primeiras páginas, com a "anacruse" da novela, quando o escritor chega à propriedade e mergulha na tranquila vida "paradisíaca", esquecendo a existência do mundo externo. Além disso, na novela, há uma passagem notável, em que o escritor, com mestria, combina verbos no tempo pretérito e verbos no tempo presente e transmite à consciência do leitor todo o plano do passado no plano do presente. Leiam com atenção: "Todos esses eventos longínquos, extraordinários, há muito foram convertidos em uma vida tranquila e retirada, ou trocados por ela, por aqueles devaneios sonolentos e ao mesmo tempo harmoniosos que 
experimentamos ao sentar na varanda rusticana..... ${ }^{9}$ Assim, é como se o passado fosse abolido, permanecesse como um presente interminável, e a vida dos senhores de terra à moda antiga apresenta-se no modelo do tempo parado.

No fragmento citado, utiliza-se ainda um procedimento refinado, que se destina a criar a impressão de prolongamento do presente: ele consiste em que Gógol, de modo inteiramente consciente, liberta os heróis e o leitor da "carga do passado". Com esse objetivo, ele introduz o motivo da amnésia, sublinhando com insistência, um tipo de "desmemória" dos cônjuges:

"Afanássi Ivánovitch serviu num destacamento cossaco, depois foi major, mas isso já faz muito tempo, já é passado, Afanássi Ivánovitch já não se lembra quase nunca disso. Afanássi Ivánovitch casou-se aos trinta anos, quando era jovem e envergava uma casaca bordada; até usou de muita astúcia para conseguir a mão de Pulkhéria Ivánovna, cujos pais não a queriam dar, mas já se lembra muito pouco disso também; ao menos, nunca fala a respeito."10

A questão, obviamente, não é a falta de memória, mas a completa indiferença em relação ao passado: como algo estranhamente distante, alheio, ele não inquieta os heróis, não lhes interessa; é simplesmente riscado da consciência. Sobre o futuro, os cônjuges refletem ainda menos, para eles o futuro também não existe. Não há passado, não há futuro, resta apenas o presente. $O$ correr do tempo é interrompido, assim como determinado pelo estatuto ao tópos "paradisíaco".

Finalmente, a impressão do tempo parado é sustentada pelo fato de que, nessa parte da novela, dominam absolutamente verbos de aspecto imperfeito, que transmitem ações repetidas, incompletas, prolongadas no tempo; e, além deles, advérbios que fortalecem seu significado, por exemplo: "normalmente", "habitualmente", "como de hábito" e outros desse tipo. Os verbos imperfeitos, com seu próprio regime, rejeitam o desenrolar

9 N. V. Gógol. "Starosvetskiie pomeshchiki". In Polnoie sobraniie sotchinenii v 14 tomakh. Moscou-Leningrado, 1937, tom 2, p. 15.

[A tradução usada é de Danilo Hora, ainda não publicada. (N. da T.)]

10 Ibidem. 
dos acontecimentos. E, realmente, nessa parte da novela, não acontece absolutamente nada, pois não é o caso de considerarmos como acontecimentos o ritual cotidiano invariável das refeições, caminhadas, horas de sono, conversas que se repetem. E assim deve ser: o acontecimento contrapõe-se organicamente à utopia; nela, a vida já foi ajustada de uma vez por todas, e qualquer violação do regulamento traz consigo uma ameaça à existência do paraíso. Pois o acontecimento é fruto da história e portador da história, ele dá movimento ao tempo; e o paraíso terrestre categoricamente não aceita a história.

Aqui chegamos justamente à segunda parte da novela, ao desenrolar e ao desfecho final. O enredo, como está colocado, começa com um acontecimento, que passa. Esse acontecimento consiste em que a gatinha da casa, à qual Pulkhéria Ivánova muito se afeiçoara, foge para as profundezas do bosque onde fica perdida três dias, depois aparece em casa completamente asselvajada, e de novo foge para o bosque, dessa vez para sempre. Prevendo que o leitor não compreenderia o acontecimento, Gógol precede seu relato de uma reflexão espacial, chamando a fuga da gatinha de "uma causa ínfima" e "um episódio dos mais insignificantes"," mas Gógol usa de astúcias, pois conhece muito bem o verdadeiro significado desse acontecimento, assim como Pulkhéria Ivánovna também entende e, após o desaparecimento da gatinha, anuncia de repente que logo morrerá. Mas como uma coisa está relacionada com a outra?

A fuga da gatinha, é claro, deve ser lida com uma chave simbólica e traz consigo alguns sentidos. Em primeiro lugar, tendo fugido para as profundezas do bosque, ou seja, para o espaço externo, a gatinha violou a fronteira da utopia, e toda violação de fronteiras do locus paradisíaco ocasiona sua destruição. Em segundo lugar, ao voltar para casa, além de ter violado a fronteira, como que "infectada" pelo espaço externo com sua selvageria e seu princípio desordenado, a gatinha traz consigo o elemento do caos e da desordem para a harmonia absoluta do cosmos paradisíaco. Justamente com essa chave é lido um

11 Ibid., p. 28. 
detalhe cheio de significados: "tornara-se uma gata selvagem naquele meio-tempo";12 em consequência disso, ela passou a recusar a carícia de Pulkhéria Ivánovna. Em terceiro lugar, a gatinha volta a ultrapassar a fronteira, que então já se tornara permeável; e, além disso, não voltou mais, preferindo, decididamente, o caos do espaço externo ao cosmos do paraíso. A negação da utopia é o meio de sua destruição. E, finalmente, o mais importante: por culpa da gatinha, transcorreu o próprio Acontecimento, que como já foi dito, é categoricamente oposto ao tempo utópico. O tempo parado de repente saiu do ponto morto e se pôs em movimento, e só podia ir em direção à morte.

As fronteiras foram violadas, o tempo se movimentou e teve início a destruição da utopia. Pulkhéria Ivánovna morreu, como ela própria previra, e a intrusão da morte assinalou a vitória final do tempo histórico. Passaram-se, como diz Gógol, "cinco anos em companhia do tempo que a tudo oblitera" - e, do paraíso terrestre, não restou nem rasto.

\section{O tempo integrador}

Esse modelo, bastante difundido na literatura, "reencarna" o passado e apresenta o passado e o presente (às vezes também o futuro) como essencialmente fundidos, geralmente no presente. Negando o caráter irreversível e ininterrupto do movimento do tempo histórico objetivo, esse modelo, em determinada medida, relaciona-se com o modelo do tempo estacionário. A diferença fundamental consiste em que o tempo integrador não rejeita, de modo nenhum, a ideia de movimento; esse modelo admite não apenas a concepção do passado como algo que já não existe e do futuro como algo que ainda não existe. Desse modo, confirma-se a ligação indissolúvel entre os tempos apresentada em imagens alegóricas ou fantásticas.

Esse modelo temporal teve ampla disseminação na poesia do neoclassicismo, inclusive do brasileiro, em que heróis nacionais contemporâneos atuam lado a lado com heróis anti-

12 lbid., p. 29. 
gos e personagens mitológicos. É claro que isso é pura alegoria, mas a alegoria também possui uma dimensão temporal ficcional.

Outras variantes desse modelo ficcional foram cultivadas no seio do romantismo, que transfere o passado "vivificado" da esfera da alegoria para a esfera do fantástico. Fazendo renascer crenças mitológicas na influência dos antepassados sobre a vida do presente, os românticos, e depois deles os criadores da literatura de massa, de lazer, cultivaram o enredo que conta como o passado, sendo um objeto material, um manuscrito, uma estátua, uma múmia vivificada, começa a exercer influência direta sobre o presente e até a determinar plenamente 0 destino dos heróis. Os enredos empolados do romance gótico (espectros de mortos, sua interferência na vida dos personagens) também são uma das variedades de personificação do tempo integrador.

Na prosa realista russa, um exemplo impressionante do modelo do tempo integrado é encontrado no conto "O estudante", de Tchekhov. Na sexta-feira Santa, um estudante de uma academia de teologia conta às mulheres da aldeia sobre a Última Ceia e o que aconteceu no Jardim do Getsêmani. «И радость вдруг заволновалась в его душе, и он даже остановился на минуту, чтобы перевести дух. Прошлое, думал он, связано с настоящим непрерывною цепью событий, вытекавших одно из другого. И ему казалось, что он только что видел оба конца этой цепи: дотронулся до одного конца, как дрогнул другой» ("E de repente uma alegria começou a se agitar em sua alma, e ele até parou por um minuto, para respirar. $\mathrm{O}$ passado, pensou ele, estava ligado a uma verdadeira corrente contínua de eventos que surge um do outro. E pareceu-lhe que ele acabara de ver os dois extremos dessa corrente: ao tocar em uma ponta, a outra estremeceu). ${ }^{13}$

Na literatura do século $\mathrm{XX}$, o modelo do tempo integrador passa por um singular desenvolvimento, encontrando novas formas de expressão, às vezes puramente fantásticas. Além disso, no século $\mathrm{XX}$, o modelo de tempo integrador recebe já

13 А.П.Чехов. Собрание сочинений в двенадцати томах. Москва, 1985. Том 8. С. 265. 
uma base filosófica. Alguns escritores apresentam a história e o tempo não como o rio de Demócrito, pelo qual não se pode passar duas vezes, mas, muito mais, como um tipo de represa enorme, de onde nada, nem pensamentos, nem ações, nem objetos materiais, corre para lugar algum e aonde é permitido "entrar" quantas vezes a pessoa quiser. Podemos afirmar que o modelo do tempo integrador está na base do romance de Bulgákov O mestre e Margarida, cuja ação decorre simultaneamente em duas dimensões temporais: a contemporaneidade (os anos 30 do século $\mathrm{XX}$ ) e o ano 33 da nossa era (a história de Cristo). $O$ passado evangélico apresenta-se não como uma "recordação", uma volta ao passado, mas como um estrato de tempo significativo por si só, que se desenvolve no imaginário do leitor e que existe no presente. Mas o presente, quando olhamos a partir do passado, apresenta-se como futuro, não pressuposto, mas realmente existente de todo. Assim, no romance, convivem simultaneamente todas as três dimensões do tempo; o impulso interior de Bulgákov consiste justamente em restabelecer a ligação perdida entre os tempos.

Para concluir, convém sublinhar dois aspectos essenciais. 0 primeiro: obviamente, os modelos do tempo ficcional nem de longe se esgotam com aqueles apresentados aqui e, além disso, também estes, na personificação artística concreta, podem se personificar numa série de variantes, podem adquirir uma ou outra nuança e traço específico. É preciso considerar também um segundo aspecto: muito raramente, a obra literária ficcional se constrói num único modelo temporal; geralmente, estão combinados nela, às vezes de modo muito caprichoso, variados modelos de tempo. Às vezes, eles se opõem um ao outro; às vezes, transbordam um sobre o outro; às vezes, fundem-se até não ser mais possível distingui-los. Não poderia ser de outro modo, pois, através do personagem, o autor reflete uma percepção subjetiva do tempo, uma percepção pessoal, viva, diversificada e variável. 


\section{Referências bibliográficas}

DOSTOIÉVSKI, F. M. Prestuplenie i nakazanie. In: Sobranie sotchinenii. Moscou, 1957. Tom 5.

ELIADE, M. Kosmos $\mathrm{i}$ istoriia. Moscou, 1987.

ELIADE, M. Siiashchennoye i mirskoie. Moscou, 1994.

ELIADE, M. Aspekti mifa. Moscou, 1995.

FREIDENBERG, O. M. Mif i literatura drevnosti. Moscou, 1978.

GUREVITCH, A. Ia. Kategorii srednevekovoi kulturi. Moscou, 1972.

GÓGOL, N. I. "Starosvetskiie pomeshchiki”. In: Polnoie sobraniie sotchinenii v 14 tomakh. Moscou-Leningrado, 1937. Tom 2.

GONTCHAROV, I. A. Oblómov. Vilna, 1954

LÉVY-BRUHL, L. Pervobitnoie michliéniie. Leningrado, 1930.

KHIUBNER, K. Istina mifa. Moskva, 1996.

LOTMAN, IU. M. "Proiskhojdeniie siujeta v tipologuitcheskom osveschenii". In: Stati po tipologuii kulturi: V 2 t. Tartu, 1973. T. 2.

MELETINSKI, Ie. M. Poetika mifa. Moscou, 1976.

MELETINSKI, Ie. M. Mifi narodnogo mira. Moscou, 1980. Tom 1. MELETINSKI, Ie. M. Ot mifa k literature. Moscou, 2001.

PÚCHKIN, A. S. Mednii vsadnik In Izbrannoie. Moscou, 1978.

STEBLIN-KAMENSKI, M. I. Mif. Moscou, 1976.

TCHEKHOV, A. P. "Student". In: Sobraniie sotchinenii v dvenadtsati tomakh. Moscou, 1985. Tom 8.

TIÚTCHEV, F. I. Izbrannoie. Moscou, 1974.

TOLSTÓI, L. N. Khadji-Murat. Moscou, 2017.

Tradução de Denise Regina de Sales ${ }^{14}$

14 Professora de Língua e Literatura Russas do Instituto de Letras da Universidade Federal do Rio Grande do Sul (UFRGS). denise.sales@ufrgs.br 
O tempo ficcional literário e seus modelos

Recebido em: 10/04/2020

Aceito em: 18/11/2020

Publicado em dezembro de 2020 